\title{
The links between sleep duration, obesity and type 2 diabetes mellitus
}

\author{
Christina Antza1,3, Georgios Kostopoulos ${ }^{\mathbb{D} 2}$, Samiul Mostafa1,3, Krishnarajah Nirantharakumar ${ }^{4,5}$ and \\ Abd Tahrani1,3,5
}

\author{
${ }^{1}$ Institute of Metabolism and Systems Research, University of Birmingham, Birmingham, UK \\ 2Department of Endocrinology, 424 General Military Hospital, Thessaloniki, Greece \\ ${ }^{3}$ Department of Diabetes and Endocrinology, University Hospitals Birmingham NHS Foundation Trust, Birmingham, UK \\ 4Institute of Applied Health Research, University of Birmingham, Birmingham, UK \\ ${ }^{5}$ Centre of Endocrinology Diabetes and Metabolism, Birmingham Health Partners, Birmingham, UK
}

Correspondence should be addressed to A Tahrani: a.a.tahrani@bham.ac.uk

\begin{abstract}
Global rates of obesity and type 2 diabetes mellitus (T2DM) are increasing globally concomitant with a rising prevalence of sleep deprivation and sleep disorders. Understanding the links between sleep, obesity and T2DM might offer an opportunity to develop better prevention and treatment strategies for these epidemics. Experimental studies have shown that sleep restriction is associated with changes in energy homeostasis, insulin resistance and $\beta$-cell function. Epidemiological cohort studies established short sleep duration as a risk factor for developing obesity and T2DM. In addition, small studies suggested that short sleep duration was associated with less weight loss following lifestyle interventions or bariatric surgery. In this article, we review the epidemiological evidence linking sleep duration to obesity and T2DM and plausible mechanisms. In addition, we review the impact of changes in sleep duration on obesity and T2DM.
\end{abstract}

\author{
Key Words \\ > obesity \\ - diabetes mellitus \\ - sleep duration \\ - long sleep \\ - short sleep \\ - sleep deprivation \\ - sleep manipulation \\ - type 2 diabetes \\ - sleep
}

\section{Introduction}

Obesity prevalence increased globally between 1975 and 2016 , from 0.7 to $5.6 \%$ in girls, from 0.9 to $7.8 \%$ in boys and from 4.7 to $13.1 \%$ in adults with big variations amongst different world regions (Abarca-Gómez et al. 2017) (https://apps.who.int/gho/data/view.main.REGION 2480A?lang=en Accessed (September) (2021)). Considering the health and economic consequences associated with obesity (type 2 diabetes mellitus (T2DM), cardiovascular disease (CVD), cancer, mortality), there is huge interest in strategies to reduce obesity prevalence (Guh et al. 2009, Lu et al. 2014, Blackman et al. 2016, Zheng et al. 2016, Asad et al. 2018, Mistry et al. 2018, Singh et al. 2020) (https://openknowledge.worldbank.org/bitstream/ handle/10986/32383/211491ov.pdf?sequence=4\&is\%20 Allowed $=y$ Accessed (September) (2021)) (https://www. weforum.org/agenda/2019/10/obesity-healthcareexpenditure-burden/ Accessed (September) (2021)).

Similar to the increase in obesity prevalence, T2DM prevalence has also increased dramatically over the last three decades, and it is predicted to reach $11 \%$ globally by 2045 (Saeedi et al. 2019) (https://www.who.int/news-room/ fact-sheets/detail/diabetes Accessed (September) (2021)). Obesity is associated with an increased risk of T2DM (Kahn et al. 2006). Similar to obesity, T2DM has a major negative health (CVD, diabetes-related microvascular complications, mortality) and economic impact (Stamler (c) 2021 The authors Published by Bioscientifica Ltd. Printed in Great Britain
This work is licensed under a Creative Commons Attribution 4.0 International License. 
et al. 1993, Brownrigg et al. 2016) (https://www.nicswell. co.uk/health-news/diabetes-cases-and-costs-predicted-torise Accessed (February) (2021)). Hence, T2DM prevention strategies are of paramount importance, and addressing obesity is key to reduce the burden of this disease (Jones et al. 2006, Milstein et al. 2007).

Despite multipleapproaches including policy (sugar tax for example), lifestyle interventions and pharmacological and non-pharmacological treatments, to contain this syndemic, the prevalence of obesity and T2DM continued to increase globally and no country has managed to reduce the prevalence of either disease. Hence, there is a need for a better understanding of the complex disease pathogenesis and improved understanding of the modifiable risk factors to reduce the burden of obesity and T2DM.

Further to the increases in the obesity and T2DM prevalence, sleep insufficiency has become part of the modern lifestyle, across all age groups (Gangwisch et al. 2005, Basch etal. 2014, Owens etal. 2014, Gordon et al. 2019, Toyoura et al. 2020). The average sleep duration dropped from 8-9 h/night in 1960 to 7 h/night in 1995 (Van Cauter \& Knutson 2008). The prevalence of short sleep duration was reported as $45 \%$ in the United States in 2014, with a third of US adults not getting enough sleep ( $<7 \mathrm{~h} /$ night), which led the Centre for Disease Control in the United $\mathrm{S}$ to labelling sleep insufficiency as a public health epidemic (https:// www.aaas.org/news/sleep-deprivation-described-seriouspublic-health-problem. Accessed (September) (2021)). This is further emphasised by the associations between short sleep and adverse health outcomes, including CVD and mortality among others (https://www.cdc.gov/sleep/ data_statistics.html Accessed (September) (2021)). Hence, improving sleep duration might be an important strategy to reduce the prevalence and economic impacts of obesity and T2DM. However, despite its potential importance, sleep disorders are largely underdiagnosed.

The relationship between sleep duration, obesity and T2DM is likely to be bi-directional. Obesity and T2DM can disrupt sleep due to the high prevalence of obstructive sleep anoea or the occurrence of hypoglycaemia or nocturnal symptoms such nocturia or painful neuropathy (Surani et al. 2015, Lavrentaki et al. 2019). In addition, changes in body weight could lead to changes in sleep duration. Clinically significant weight loss was found to be associated with decreased daytime sleepiness and time to fall asleep, and increased sleep duration in people with short sleep duration ( $\leq 7 \mathrm{~h}$ ) (Verhoef et al. 2013). In this article, we critically review only the evidence linking sleep duration to obesity and T2DM, with a particular focus on the epidemiology and interventional studies to examine whether manipulating sleep duration can be utilised as a strategy to prevent or treat obesity and T2DM. We will also review recent evidence regarding the mechanisms linking sleep duration to obesity and T2DM.

\section{Methods}

We performed a scoping literature search using Medline, the Cochrane Library, CINAHL and PsycINFO from inception to 31 August 2021, to identify studies that examined the relationship between sleep duration and obesity as well as sleep duration and T2DM (PICO question is presented Supplementary content 1 , see section on supplementary materials given at the end of this article). We used appropriate search terms that had been identified from initial scoping searches, target references, and browsing of database thesauruses (sleep duration and diabetes (Supplementary content 2). A basic search strategy was developed for PubMed and modified accordingly for other research engines. This review will mainly focus on cohort and interventional studies. We utilized meta-analyses and systematic reviews where available and summarised the evidence that was not included in the latest systematic reviews.

\section{Assessing sleep duration}

Self-reported sleep duration is widely used in research and clinical practice due to its ease of use and the ability to apply it to large population. However, the increasing availability of modern technology aiding better assessments of sleep highlighted the shortcomings of self-reported sleep duration. Self-report does not reflect the objectively measured sleep. A study of more than 5000 participants, aged more than 65 years old, showed a poor agreement between self-reported and actigraphic sleep duration (Kappa $\leq 0.24)$. Nearly half of the patients who reported normal sleep had short sleep on actigraphy and more than a quarter of participants that reported short sleep had normal sleep on actigraphy (Miner et al. 2021). These discrepancies between subjective and objective measures of sleep duration were observed in multiple ethnicities including Whites, Blacks, Hispanics and Chinese (Jackson et al. 2018). In another study of 2086 participants in the United States, self-reported sleep duration was significantly greater than actigraphy-measured sleep duration (7.85 $\pm 1.12 \mathrm{~h}$ vs $6.74 \pm 1.02 \mathrm{~h}$, respectively) (Cespedes et al. 2016b). Correlations between self-reported

This work is licensed under a Creative Commons Attribution 4.0 International License.

ded from Bioscientifica.com at 04/26/2023 05:55:26AM via free access 
and actigraphy-assessed time spent asleep were lower with male sex, younger age, sleep efficiency $<85 \%$ and night-tonight variability in sleep duration $\geq 1.5 \mathrm{~h}$.

Hence, the limitations of self-reported sleep duration need to be considered when interpreting the studies listed in this review.

\section{Epidemiological studies}

\section{Sleep duration and obesity}

\section{Sleep duration as a risk factor for obesity}

Cross-sectional studies showed conflicting results regarding the relationship between sleep duration and obesity ranging from linear or U-shaped associations to no relationship (Yan et al. 2017, Rosique-Esteban et al. 2018, Park et al. 2020). This difference can be in part due to the impact of age on the relationship between sleep duration and obesity and differences in the methods of assessing sleep duration or obesity (objective vs subjective) (Yan et al. 2017, Rosique-Esteban et al. 2018, Park et al. 2020). The association between short sleep and obesity is stronger in children compared to adults and in younger adults compared to older adults. Variation regarding this association could also be attributed to different anthropometric measurements applied in obesity definitions, such as BMI, waist circumference (WC) and abdominal adiposity.

Unlike cross-sectional studies, the results of cohort studies have been more consistent. Multiple metaanalyses of cohort studies in the last 10 years examined also the relationship between sleep duration and the risk of developing obesity in adults and children (Table 1) (Wu et al. 2014, 2017, Capers et al. 2015, Fatima et al. 2015, Ruan et al. 2015, Sperry et al. 2015, Itani et al. 2017, Li et al. 2017, Jike et al. 2018, Deng et al. 2021, Guo et al. 2021, Miller et al. 2021).

All the meta-analyses (whether adults or children) of cohort studies had large sample sizes (from 15,000 to 200,000). The length of follow-up varied from 0.5 to 34 years. Sleep duration was mostly self-reported (or parent-reported in children studies). Two meta-analyses performed sensitivity analyses excluding studies in which sleep duration was objectively measured (Bacaro et al. 2020, Zhou et al. 2020). To our knowledge, there is not any available meta-analysis to use exclusively normal weight children in the eligibility criteria in order to identify the possibility of obesity in adulthood. However, the outcomes were adjusted to baseline BMI.
Based to cohort-included meta-analytic data, short sleep duration has been consistently associated with increased risk of obesity (whether defined based on BMI or WC). On the other hand, the association between long sleep duration and obesity was not consistent and some meta-analyses showed no associations. Multiple definitions of short sleep duration were used, but all definitions $(<7,<6,<5,<4 \mathrm{~h} /$ night) were associated with increased risk of obesity in adults (Itani et al. 2017). The shorter the sleep duration, the higher the risk of obesity; the pooled relative risk (RR) for obesity was 1.09 (95\% CI, 1.05-1.14) per 1-h decrement of sleep duration compared to 7-8 h (Itani et al. 2017, Zhou et al. 2019). The association between sleep duration and obesity was consistent among multiple subgroups analyses, such as age, gender, ethnicity, follow-up time, quality of study and BMI cut-offs. Notably, sleep duration seemed to have a greater impact on adiposity in female gender. The latter might be attributed to different hormonal profile and socioeconomic status (Zhou et al. 2020).

In addition, people with short sleep duration or poor sleep quality lost less fat mass, while having a $600 \mathrm{kcal}$ restricted diet during a longitudinal study over 24 weeks (Chaput \& Tremblay 2012). For each additional hour of sleep, fat loss increased by $0.77 \%$ or $0.72 \mathrm{~kg}$. Moreover, data from a small pilot study (14 patients who underwent bariatric surgery) highlight the role of sleep in long-term weight loss maintenance at 6 and 9 years post-surgery (Zuraikat et al. 2019). Sleep duration was inversely related to BMI at 6-year follow-up $\left(\mathrm{R}^{2}=0.41\right.$, adjusted $\mathrm{R}^{2}=0.36$, $P=0.02)$ but not at 9-year follow-up $\left(\mathrm{R}^{2}=0.27\right.$, adjusted $\left.\mathrm{R}^{2}=0.21, P=0.055\right)$ suggesting that short sleep was associated with greater weight regain after bariatric surgery.

Hence, short sleep not only might increase the risk of developing obesity but might also affect the outcome of weight loss interventions. Whether sleep manipulation when combined with weight loss interventions enhance the outcomes of these interventions need to be examined in randomised controlled trials (RCTs).

\section{The relationships between changes in sleep duration and obesity}

Although short sleep duration is an independent risk factor for obesity, it is important to examine whether changes in sleep duration could mitigate the burden of obesity or not, but such evidence is limited. In a small study with a follow-up duration of 6 years, based on the cohort of Quebec Family Study, patients with short sleep duration at baseline ( $\leq 6 \mathrm{~h} /$ night, $n=43$ ) were categorised into two groups: those who increased their sleep duration to $7-8 \mathrm{~h} /$

This work is licensed under a Creative Commons Attribution 4.0 International License. 


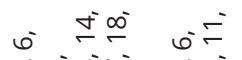

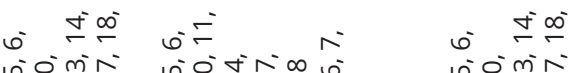

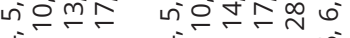

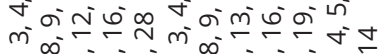

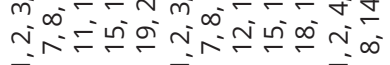

nioni

बंज 0

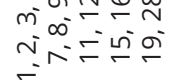

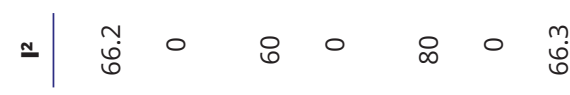

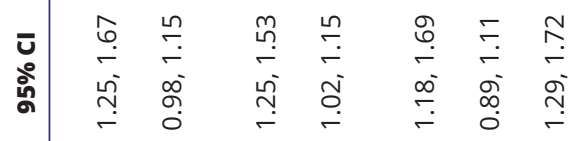
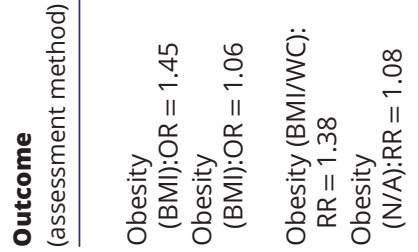

西
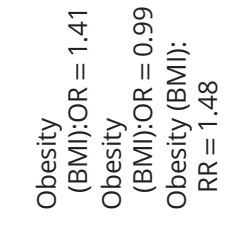

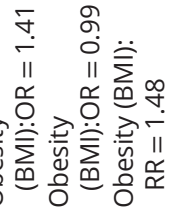

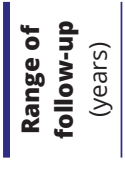

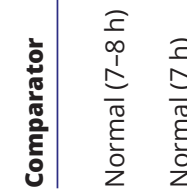

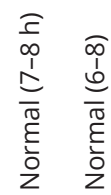

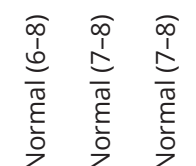

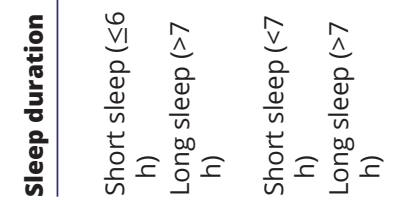

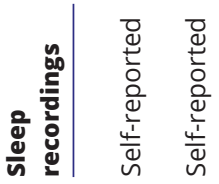

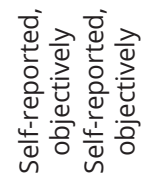

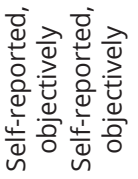

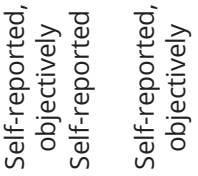

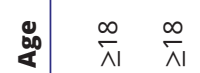

$\stackrel{\infty}{\wedge 1} \stackrel{\infty}{\wedge}$

है⿴囗十心

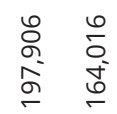

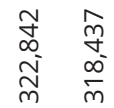

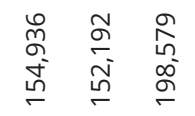

हैं

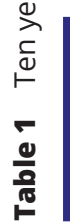

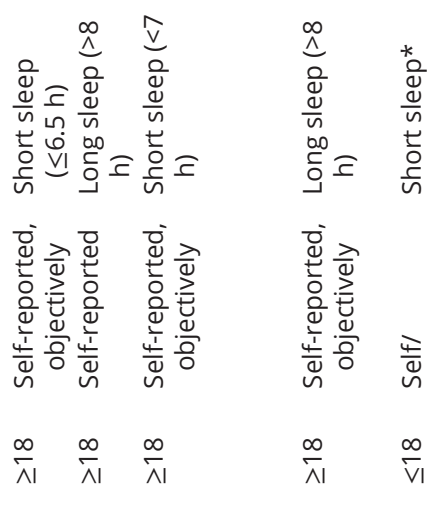

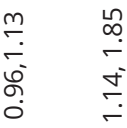

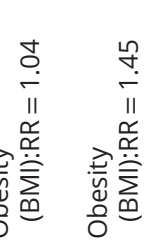

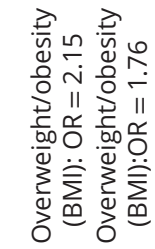

$\stackrel{\substack{1 \\ I}}{\stackrel{1}{1}}$

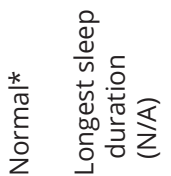

$\frac{\frac{k}{\pi}}{\frac{\pi}{2}}$

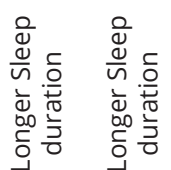

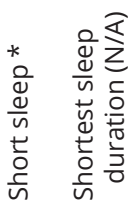

$*$
$\stackrel{0}{0}$
$\frac{\tilde{U}}{n}$
$\bar{t}$
$\frac{0}{4}$

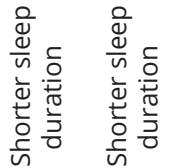

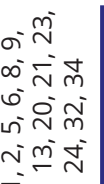




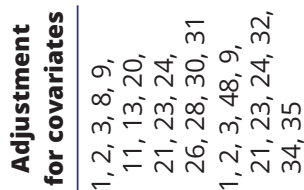

$\simeq \mid \begin{array}{lll}\infty & \sigma & m\end{array}$

บ

ณัे

$\infty$

ஸे

ñ
o.
ก.
م.

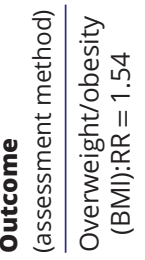



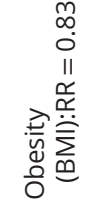

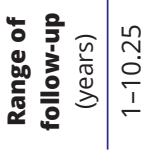

$\begin{array}{ll} & \stackrel{n}{N} \\ \stackrel{1}{ } & \stackrel{1}{r}\end{array}$
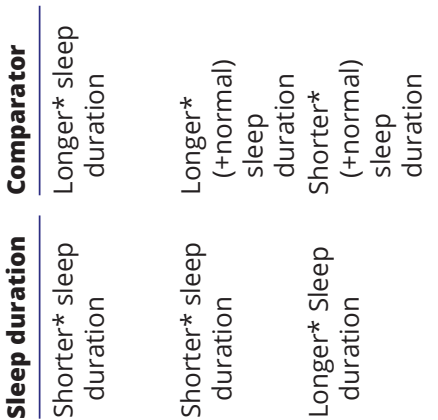

$\sqrt{ }$

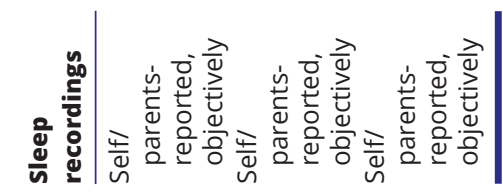

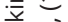

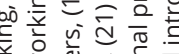

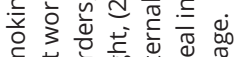
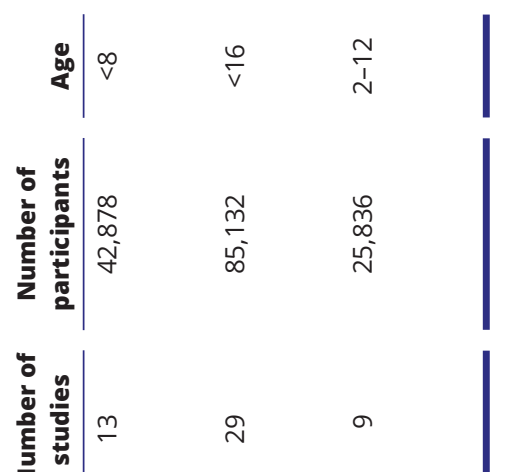

จ

$a$
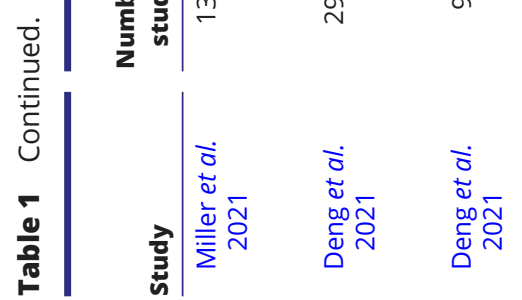

night (mean increase $1.52 \pm 0.66 \mathrm{~h} /$ day) and those who did not altered their short sleep duration over the follow-up. The control group in this study was 173 people with 7-8 $\mathrm{h} /$ night sleep duration. Over the 6 years follow-up, the control group had the smallest increase in BMI (mean (S.E.) $0.8 \pm 0.15 \mathrm{kgm}^{-2}$ ), fat mass (mean (S.E.) $0.75 \pm 0.35$ $\mathrm{kg}$ ) and waist circumference (mean (s.E.) $2.4 \pm 0.45 \mathrm{~cm}$ ) compared to the other two groups (approximation with WebPlotDigitizer 4.4 for Mac). Short sleepers who did not increase their sleep duration had greater increase in BMI (mean difference $1.1 \pm 0.36 \mathrm{~kg} \mathrm{~m}^{-2}, P<0.05$ ), fat mass $(2.4 \pm 0.64 \mathrm{~kg}, P<0.05)$ and waist circumference (mean difference $1.4 \pm 1.1 \mathrm{~cm}$ (approximation with WebPlotDigitizer 4.4 for Mac), $P=0.09$ ) compared to short sleepers who increased their sleep duration, after adjusting for age, sex, baseline BMI, smoking habits, energy intake and physical activity (Chaput et al. 2012). The increase in adiposity measures in those with short sleep that increased their sleep duration was similar to the control group (Chaput et al. 2012). The sleep duration in this study was self-reported, and the reasons for sleep change were not examined. This is important as the 'trigger' to change sleep duration might be related to the changes in BMI (Chaput et al. 2012).

However, the Nurses Health Study showed that prolonging self-reported sleep by $\geq 1 \mathrm{~h} /$ day was associated with weight gain (Cespedes et al. 2016a). The Nurses Health Study followed up 59,013 women aged 55-83 years between 1986 and 2000. Changes in sleep duration were self-reported. The analysis was adjusted for race/ ethnicity, baseline sleep duration, age, employment status, menopause, alcohol, smoking, diabetes family history, snoring frequency, sleep apnoea diagnosis, antidepressant use, shift work history, BMI and hypertension or hypercholesterolaemia.

After adjustment, and compared to the reference category (no change in sleep duration), an increase in sleep duration by $1 \mathrm{~h} /$ day and $2 \mathrm{~h} /$ day were associated with increase in weight $(\mathrm{kg})$ (mean $(95 \% \mathrm{CI}) ; 0.31(0.15,0.47)$ and $0.47(0.21,0.72)$ for 1 and $2 \mathrm{~h}$, respectively) (Cespedes et al. 2016a). However, these findings need to be interpreted within several limitations including that the sleep duration was self-reported, and the weight was reported at two timepoints (study start and end). Hence, variations in weight could not be captured. More importantly, the changes in weight described are relatively small considering the long follow-up and unlikely to be clinically meaningful. In addition, considering the age of the study population and the follow-up duration, sarcopenia might contribute to the changes in weight and the observed 
increase in weight might represent an underestimate of adiposity due to the lack of body composition data. The analysis also was not performed in specific sub groups such as people with obesity or people with short sleep duration at baseline (Cespedes et al. 2016a).

Hence, the evidence from epidemiological studies does not provide clear evidence regarding the relationship between changes in sleep duration and adiposity. As a result, interventional studies are needed to answer the questions whether sleep duration manipulation can reduce obesity or weight. These are discussed in section 4 of the review.

\section{Sleep duration and type 2 diabetes mellitus}

\section{Sleep duration as a risk factor for type 2 diabetes and gestational diabetes}

Evidence from cross-sectional studies suggests a U-shaped association between sleep duration and T2DM. Short sleepers (5-6 h/day) have 2 times higher odds of being diagnosed with prediabetes and T2DM, while long sleepers are almost at a $60 \%$ higher odds of developing T2DM, compared to normal sleepers (7-8 h/day) (Chaput et al. 2007b, Engeda et al. 2013). The findings remained unchanged even after adjustment for confounders such as age, BMI and WC. Similarly, meta-analytic data show that long ( $>9 \mathrm{~h} /$ day) and especially short sleep ( $<6-7 \mathrm{~h} /$ day) are associated with increased risk of gestational DM (GDM) (Xu et al. 2018).

Meta-analyses of cohort studies published in the latest 10 years examining sleep duration and T2DM are summarised in Table 2. All the meta-analyses were in adults and included a very large number of participants. Sleep duration was self-reported in all the studies and the definitions of short and long sleep were variable. Almost all the studies were adjusted for BMI or another obesity measure. However, this may still not completely account for the effects of obesity in this correlation. Furthermore, this summary of current meta-analyses shows a major weakness of sleep research, which is the focus on single sleep disorder in isolation without accounting for the high possibility of coexistent sleep disorders, which could affect the outcomes. This is apparent in the adjustments details in Table 2, where there have been little adjustments for other sleep disorders and only a handful adjusted for napping. All the meta-analyses showed that short sleep duration increased the risk of T2DM and most (except one) showed that long sleep duration was associated with increased risk of T2DM. In addition, two meta-analyses showed conflicting results regarding the relationship between short sleep duration and risk of GDM, while one meta-analysis showed significant association between long sleep duration and risk of GDM (Cappuccio et al. 2010, Holliday et al. 2013, Shan et al. 2015, Anothaisintawee et al. 2016, Lee et al. 2017, Reutrakul et al. 2018, Xu et al. 2018).

Regarding the relationship between short sleep duration and T2DM, the results were consistent in subgroup analyses by ethnicity (Shan et al. 2015) and sleep duration (Cappuccio et al. 2010, Itani et al. 2017). Men were more vulnerable to the relationship between short sleep duration and incident T2DM compared to women (Cappuccio et al. 2010, Itani et al. 2017). Similarly, consistency of findings summarizing the impact of long sleep on risk of developing T2DM was depicted in subgroup analyses by sex (Cappuccio et al. 2010, Jike et al. 2018), ethnicity (Shan et al. 2015) and sleep duration (Cappuccio et al. 2010, Jike et al. 2018).

The importance of sleep-related disorders (such as insomnia, sleep apnoea, sleep duration) as risk factors for T2DM was highlighted in a meta-analysis that examined risk factors for the development of T2DM (Anothaisintawee et al. 2016). This meta-analysis showed that after obesity and family history, sleep-related disorders had greater effect sizes in terms of T2DM risk compared to physical inactivity. In particular, the age, sex and BMI adjusted HRs for the developing T2DM in short ( $\leq 5 \mathrm{~h})$ and long ( $\geq 9 \mathrm{~h}$ ) sleep duration and physical inactivity were $1.45,1.41$ and 1.20, respectively (Anothaisintawee et al. 2016).

Interestingly, two meta-regressions found no doseresponse relationship between short and long sleep duration and incident T2DM (Itani et al. 2017, Jike et al. 2018). This does not necessarily imply the absence of significant relationship but might possibly be attributed to the lack of published studies for the outcome of interest.

\section{Sleep duration in patients with type 2 diabetes mellitus}

Recent data from cross-sectional studies showed that short and long sleep durations were associated with diabetic retinopathy and albuminuria (Jee et al. 2017, Tan et al. 2018). Furthermore, in people with T2DM, several studies showed an association with short or long sleep duration and worse glycaemic control. A recent meta-analysis of cross-sectional studies examined the association of sleep duration on haemoglobin A1c (HbA1c) in people with T2DM (Lee et al. 2017). Results showed that people with habitual short sleep duration $(<4.5-6$ h per night) had significantly higher levels of HbA1c (mean difference: $0.23 \%$ 95\% CI: 0.10-0.36) compared to normal sleep duration (reference group of 6-8 h per night).

This work is licensed under a Creative Commons Attribution 4.0 International License. 


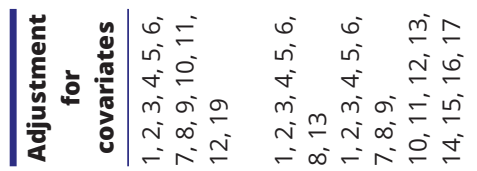

$\simeq \mid \stackrel{\infty}{n} \tilde{m} \stackrel{n}{r}$ in

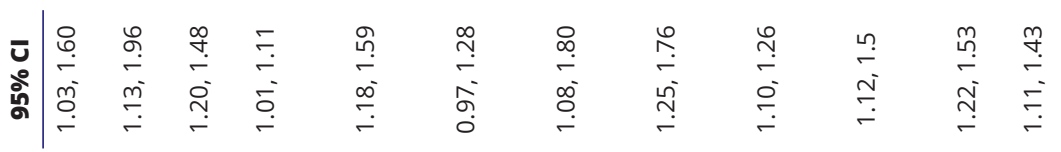

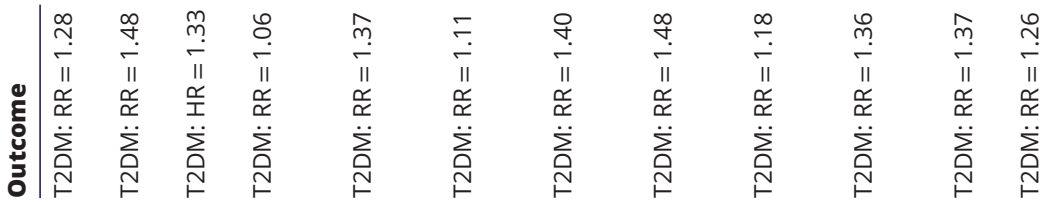

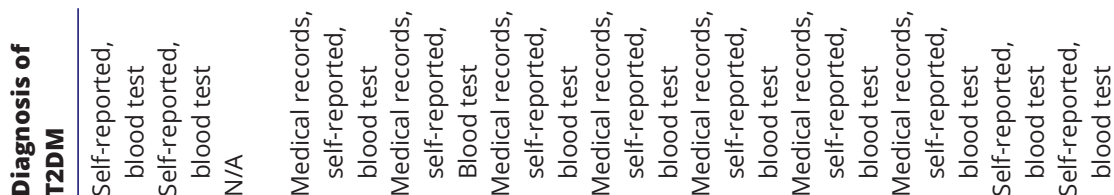

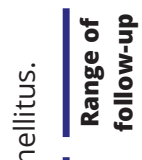

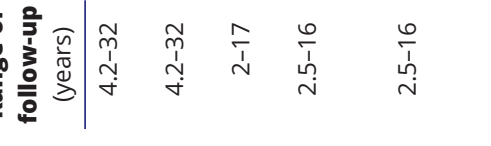

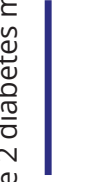

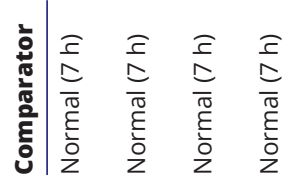

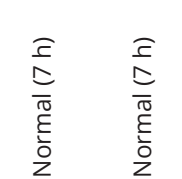

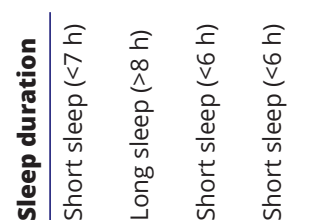

$\frac{a}{n}$
vil
$\frac{0}{d}$
$\frac{d}{n}$
$\frac{t}{0}$
$\frac{o}{n}$

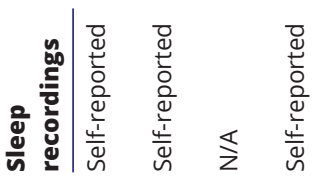

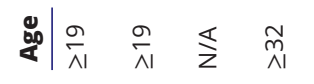

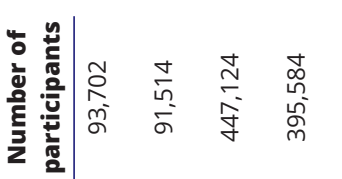

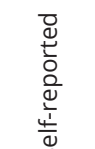

ำ

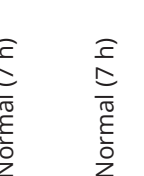

$\frac{\sqrt{2}}{\frac{1}{5}}$

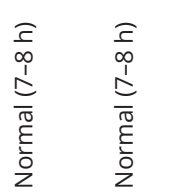

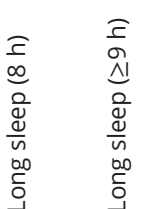

돈

ㄴ.

$\frac{\circ}{\frac{0}{n}}$

$\frac{n}{n}$

임

$\frac{2}{21}$

ज $\quad \stackrel{\frac{1}{N}}{\sim}$

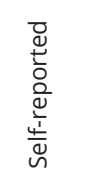

$\stackrel{\sim}{\sim} \quad \stackrel{\sigma}{\pi} \quad \frac{\sigma}{\wedge 1}$

$\stackrel{\infty}{\wedge}$

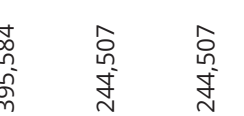

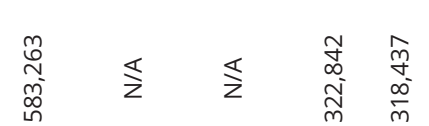

离

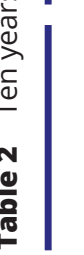

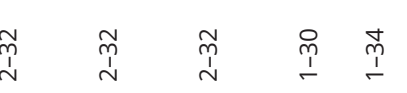

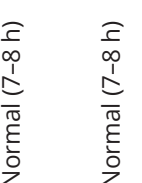

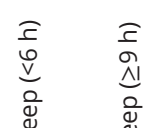

$\frac{\pi}{\frac{\pi}{n}}$

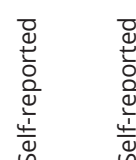

$\frac{\infty}{N}$

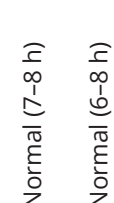

$\infty \stackrel{\infty}{\wedge}$

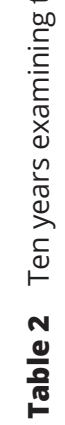

https://joe.bioscientifica.com

(c) 2021 The authors Published by Bioscientifica Ltd.
Printed in Great Britain

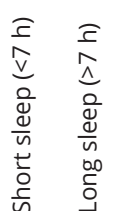

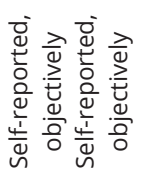

(1)

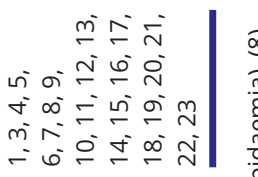

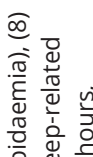

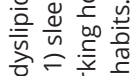

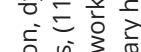

品

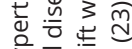

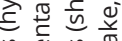

है

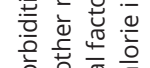

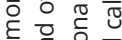

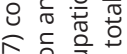

ᄃ

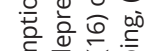

帘 $\frac{0}{0} \frac{0}{0} \frac{0}{0}$

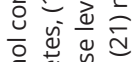

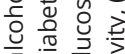

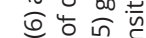

aio $\geq 5$

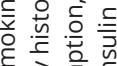

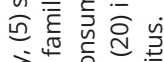

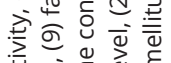

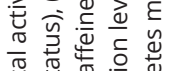

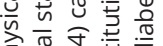

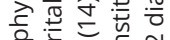

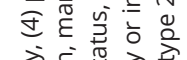

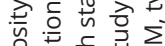

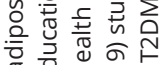

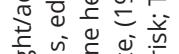

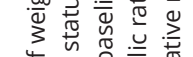

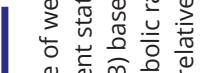

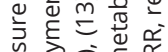

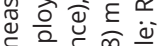

है है

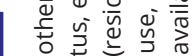

एँ

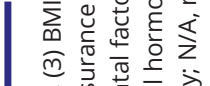

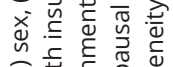

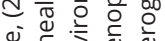

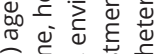

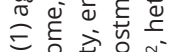

凶ّ

告

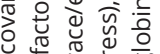

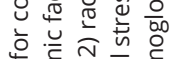

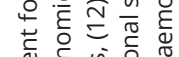

क v

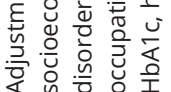


Si,milarly, long sleep ( $>8-9 \mathrm{~h}$ per night) was associated with higher levels of HbA1c (mean difference: 0.13\%, 95\% CI: 0.02-0.25), as well. However, not all the reported findings from the studies included in the quantitative synthesis were adjusted for confounders (obstructive sleep apnea, obesity or depression), and the observed differences are modest and potentially unimportant clinically, which represent a limitation of this meta-analysis.

\section{The links between changes in sleep duration and type 2 diabetes prospectively}

While short sleep duration has been shown consistently in multiple studies to be associated with increased risk of T2DM, studies examining the relationship between changes in sleep duration and incident T2DM did not support the findings of the above-discussed meta-analyses. This could be due to a true lack of effect or to specific reasons related to the populations studied and methods used. For example, these studies did not account for other sleeprelated disorders which might also have an impact on the development of T2DM. The adjustment for confounders was variable and the increase in sleep duration examined in these studies was not necessary in people with short sleep duration at baseline. Summary of these studies is detailed below.

The Nurses Health Study (detailed above) showed that compared to no change in sleep duration, increased sleep by $2 \mathrm{~h}$ /day was associated with increase in the risk of T2DM after adjustment (detailed above) (HR (95\%CI) (1.15 (1.01, 1.30), $P=0.03$ ) (Cespedes et al. 2016a). An increase in sleep duration by $1 \mathrm{~h} /$ day was not significantly associated with higher risk for T2DM (Cespedes et al. 2016a).

Similar findings were reported in the Whitehall II Study. An increase of $2 \mathrm{~h}$ or greater in sleep duration over a period of 5 years was associated with an increased risk of T2DM after adjustment for age, sex, ethnic group, employment grade, and change in BMI ( $\mathrm{OR}=1.50,95 \% \mathrm{CI}$ : 1.04-2.16) compared to a stable $7 \mathrm{~h} /$ night sleep (Ferrie et al . 2015). Sleep duration was self-reported, and the diagnosis of T2DM was based on the criteria of WHO in 2006 and 2011 (Ferrie et al. 2015).

Another prospective cohort study, the Kailuan study, evaluated the effect of sleep changes over a biennial follow-up and the risk for T2DM. Almost 60,000 patients were included, with the reference category stable normal sleepers ( $7 \mathrm{~h} / \mathrm{night}$ ). Participants who increased their sleep duration, more than $2 \mathrm{~h}$ during a period of 2 years, were more likely to develop DM after adjustment for age, sex, sleep duration at baseline, marital status, smoking status, physical activity, history of diabetes, BMI, hypertension, dyslipidaemia $\quad(H R=1.24,95 \% \quad C I: \quad 1.05-1.48)$. Sleep duration was evaluated with standardised questionnaires; T2DM diagnosis was based on the criteria of ADA in 2014 (Song et al. 2016).

Hence, the epidemiological data does not suggest that sleep prolongation can reduce the risk of T2DM. However, these studies had significant limitations and interventional studies are needed to answer the questions whether manipulating sleep duration can be used to prevent and reduce the burden of T2DM. The age of the study population in the Nurses Health Study and the Whitehall II study might have contributed to these studies findings considering the higher risk of T2DM during the follow-up due to older age and the potential development of sarcopenia and the coexistence of other sleep disorders (such as sleep apnoea) which has not been accounted for in the analysis.

\section{Intervention studies}

In this section, we describe whether sleep manipulation is feasible and the impact of sleep manipulation on obesity and/or T2DM, with particular emphasis on sleep manipulation using non-pharmacological approaches.

\section{Can sleep duration be manipulated?}

Several pharmacological and non-pharmacological interventions, aiming to improve sleep duration and quality, have been investigated over the years. Sleep aid drugs such as benzodiazepines, sedative antihistamines, barbiturates and melatonin analogues are widely prescribed (Chong et al. 2013). However, long-term use of hypnotics has been associated with serious adverse events like increased risk of death and cancer (Kripke et al. 2012). On the other hand, non-pharmacological interventions including the use of behavioural or psychological strategies have also been attempted. Sleep extension or restriction, sleep education, sleep hygiene education and cognitive behavioural therapy have all been studied (Koch et al. 2006, Mindell et al. 2006, Langford et al. 2012, Douglas \& Hill 2013, Halal \& Nunes 2014, Meltzer \& Mindell 2014, Knowlden et al. 2016, Salm \& Balfour 2016, France et al. 2018). The sleep hygiene education includes interventions such as changes in sleep environment, consistent bed- and wake-up time, avoiding behaviours affecting sleep (e.g. watching television in the bed) and activities during day helping the sleep onset (Halal \& Nunes 2014).

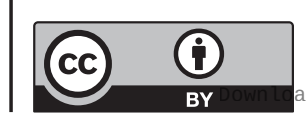

This work is licensed under a Creative Commons Attribution 4.0 International License. 
Sleep hygiene education was found to be effective in prolonging sleep duration in people with short sleep in the study by Tasali et al. (2014). In short, sleepers who have overweight but otherwise healthy (ten adults, $<6.5 \mathrm{~h}$ per night) were studied for 2 weeks and personalised sleep hygiene tips were provided from a specialist, at the first day of the intervention. At the end of the intervention, the mean sleep duration of the participants (based on actigraphy) increased from $5.6 \pm 0.1 \mathrm{~h}$ to $7.1 \pm 0.1 \mathrm{~h}(P<0.01)$ in real life settings (Tasali et al. 2014). This was associated with a $4 \%$ decrease in overall appetite $(P=0.030)$ and $62 \%$ decrease in desire for sweet and salty foods $(P=0.017)$.

In a free-living, 4-weeks, parallel-design RCT study, 42 healthy adults with normal weight and short sleep duration ( $<7 \mathrm{~h} /$ night) were randomised to either maintaining their sleep duration or sleep extension by following sleep hygiene education, including the importance of sleep, current sleep recommendations (7-9 h) and the concept of sleep hygiene, from a health psychologist. Sleep was also assessed objectively by wrist actigraphy. At the end of the study, the intervention group had an increase in time-inbed (55 min), sleep period (47 min) and sleep duration (21 min) compared to the control group (Al Khatib et al. 2018). This resulted in favourable changes to energy intake similar to that observed in the study by Tasali et al. including reduced intake of free sugars, fat, and carbohydrates.

Hence, these studies showed that sleep extension using simple non-pharmacological interventions is feasible and can be examined in RCTs.

\section{Sleep extension to prevent and treat obesity}

Limited number of studies examined the impact of sleep manipulation on weight or adiposity. These studies largely had small sample sizes and were of short duration but they provide the basis to conduct large RCTs.

A recent systematic review provided a summary of seven studies examining the impact of sleep extension interventions on cardiometabolic risk factors (Henst et al. 2019). Changes in anthropometric measures, namely BMI, weight, WC and percentage body fat, were investigated in three studies. The results were consistent among studies, as no significant changes were documented in anthropometric parameters.

In two of those studies (Leproult et al. 2015, Al Khatib et al. 2018), sleep extension in people with habitual short sleep did not result in weight loss, but these studies were of short follow-up (4-6 weeks). Similarly, in a RCT including 22 people with pre- or stage 1 hypertension and short sleep duration $(<7 \mathrm{~h} /$ day $)$, patients were randomised to maintaining their sleep habits or a sleep extension group (sleep hygiene counselling). The overall sleep time was increased by $31( \pm 9) \mathrm{min}$, but there was no effect on BMI (mean difference $=0.2, P=0.14$ ) over 6 weeks (Haack et al. 2013). Additionally, no impact of sleep extension on total body fat and WC was reported (Haack et al. 2013, Al Khatib et al. 2018). The lack of effect of sleep manipulation on improving adiposity outcomes could be due to a true lack of effect, but it could be related to the study methods as the participants recruited were not overweight or obese at baseline and studies were short-term.

The aforementioned systematic review also summarised studies focusing on other outcomes that predispose to obesity, such as dietary intake and appetite. Evidence from two RCTs reporting on dietary intake is conflicting (Haack et al. 2013, Al Khatib et al. 2018). In a RCT, sleep extension in healthy participants over 6 weeks, resulted in reduction in free sugar intake (9.6 g/day, 95\% CI: $-16.0,-3.1)$, compared to the control group in which the intake remained unchanged (Al Khatib et al. 2018). Moreover, the percentage of daily calorie intake from protein significantly increased from baseline between the intervention and control group (mean difference $3.4 \%$, 95\% CI: 0.6, 6.2). A trend towards lower fat and carbohydrate consumption compared to the control group was also reported in this study. On the other hand, in the RCT by Haack et al. (described above) sleep extension did not have an impact on dietary intake of protein, fat and carbohydrate intake (Haack et al. 2013). In another study without a control arm by Tasali et al. (described above) sleep extension in ten adults with obesity and short sleep duration was associated with a decrease in appetite by $4 \%$ and desire for sweet and salty products by $65 \%$ (measured with validated visual analog scales), while desire for fruits and vegetables remained unchanged (Tasali et al. 2014).

Despite the above conflicting results, studies and trials in people with obesity or overweight who were receiving a weight loss intervention suggest that sleep extension may have a role to play in terms of improving weight and fat loss. Two observational studies detailed above showed that short sleep was associated with less fat loss during calorie restricted diet and greater weight regain following bariatric surgery (Chaput et al. 2012, Zuraikat et al. 2019).

In a RCT, 49 patients with overweight or obesity ( $50 \%$ in the age group of $40-64$ years and BMI class of $35-40 \mathrm{~kg} / \mathrm{m}^{2}, \sim 85 \%$ women) were randomised to cognitive behavioral therapy (CBT) or CBT with better sleep intervention and were followed-up over 12 weeks. People who received better sleep intervention participated in a curriculum of dietary-, exercise- and sleep-related topics

This work is licensed under a Creative Commons Attribution 4.0 International License. 
with the goal to embrace healthier sleep habits and hence weight reduction. The mean percentage weight loss was greater in the intervention group compared to CBT alone ( $5 \%$ vs $2 \%, P=0.04)$ (Logue et al. 2012 ).

In a two-conditions crossover RCT, ten patients who had overweight were put on 14 days of moderate calorie restriction (based on $90 \%$ of the resting metabolic rate) and were randomised to $8.5 \mathrm{~h} /$ night vs $5.5 \mathrm{~h} /$ night sleep duration. Sleep duration was objectively assessed (polysomnography) in the laboratory environment. There was no difference in weight loss between the two sleep durations, which is not surprising considering the short study duration and the sample size. However, the $5.5 \mathrm{~h} /$ night was associated with less fat mass loss and greater fatfree mass loss compared to the $8.5 \mathrm{~h} /$ night. Furthermore, sleep restriction was accompanied by increased ghrelin and hunger and decreased sympathetic activity and resting metabolic rate (Nedeltcheva et al. 2010).

Hence, there is a need for well-conducted RCTs to assess the impact of sleep manipulation on adiposity in people with obesity and short sleep duration receiving weight loss interventions as well as studies to examine the role of sleep manipulation in obesity preventions.

\section{Sleep extension to prevent and treat type 2 diabetes mellitus}

There is very little literature regarding the impact of sleep manipulation on T2DM risk or diabetes-related outcomes in people with $\mathrm{DM}$.

An uncontrolled study of 16 participants (median (IQR) age $25(23,27.8)$ years, BMI $20.8(19.2,23.9) \mathrm{kg} / \mathrm{m}^{2}, \approx 20 \%$ men, self-reported sleep duration $<7 \mathrm{~h} /$ night) investigated sleep extension in real life and its impact on glucose metabolism. Sleep extension was scheduled individually, according participant's lifestyle (habitual sleep/wake cycle, work schedules, and hobbies), but all were instructed to avoid exercise $<2 \mathrm{~h}$ before bedtime. The study contained two phases: 2 weeks of habitual time in bed followed by 6 weeks during which participants were instructed to increase their time in bed by 1 hour per day. Sleep was assessed using self-reporting and actigraphy. Sleep time increased significantly during/by study end mainly during weekdays (self-reported: from $6.3 \pm 0.5 \mathrm{~h} /$ night to $7.4 \pm 0.7 \mathrm{~h} /$ night $(P<0.0001)$; actigraphy: sleep duration increased by $44 \pm 34 \mathrm{~min}(P<0.0001))$. There was no significant difference between pre- and post-intervention in fasting glucose and insulin levels. However, the percent changes in sleep duration (based on polysomnography) correlated significantly with the percent changes in fasting glucose $(r=0.53, P=0.041)$ and insulin levels $(r=-0.60$, $P=0.025)$. In addition, sleep extension was associated with improvement in insulin sensitivity (QUICKI $r=0.76$, $P=0.002$ ) (Leproult et al. 2015).

As acute sleep restriction is capable to worsen insulin sensitivity in normal sleepers, Killick et al. investigated the effect of sleep recovery. Specifically, a randomised, crossover study was conducted and a total of 19 healthy males (28.6 \pm 2 years old, BMI $26 \pm 0 \cdot 8 \mathrm{~kg} / \mathrm{m}^{2}$ ) underwent two of the three following conditions: Friday night to Monday morning of (A) $10 \mathrm{~h}$ in bed each night, (B) $6 \mathrm{~h}$ in bed each night or (C) $10 \mathrm{~h}$ in bed with slow wave sleep suppression by acoustic stimuli each night. Two weeks prior to a study weekend visit, subjects were asked to keep their regular 'catch-up' sleep-wake schedules at home and records were conducted with both actigraphy and diaries. The study was performed in laboratory setting, with room lights on and offs to guide the participants to wake or sleep, while polysomnography was recorded. Meal times, quality and quantity of the food were standardised in each intervention. Insulin sensitivity was significantly increased following three nights of $10 \mathrm{~h}$ sleep compared to continuing sleep restriction $(6 \mathrm{~h})\left(8.6 \mathrm{vs} 1.1 \times 10^{4} / \mathrm{min} / \mu \mathrm{U} / \mathrm{mL}(P=0.03)\right)$. There were no significant differences between $10 \mathrm{~h}$ in bed with slow wave sleep suppression and either $10 \mathrm{~h}(P=0.17)$ or $6 \mathrm{~h}$ $(P=0.6)$. However, taking into account that the study was laboratory based, these findings may not be applicable in real life conditions (Killick et al. 2015).

The data summarised above suggest that sleep extension might play a role in improving insulin sensitivity and hence might play a role in T2DM prevention. However, this evidence has significant limitations related to sample size, follow-up duration and generalisability of the findings. Hence, there is a need for RCTs to examine sleep manipulation as a strategy to prevent T2DM and its impact on glycaemic control and other metabolic and vascular outcomes in patients with T2DM.

\section{Mechanisms}

In this section, we discuss the potential mechanisms linking sleep duration to obesity and T2DM. There are multiple plausible mechanisms that lead to changes to energy balance, beta cell function and insulin resistance (Fig. 1).

\section{Changes to energy intake and expenditure}

Population-based and experimental studies showed that short sleep duration or partial sleep deprivation are associated with increased hunger and increased appetite

This work is licensed under a Creative Commons Attribution 4.0 International License.

ded from Bioscientifica.com at 04/26/2023 05:55:26AM 


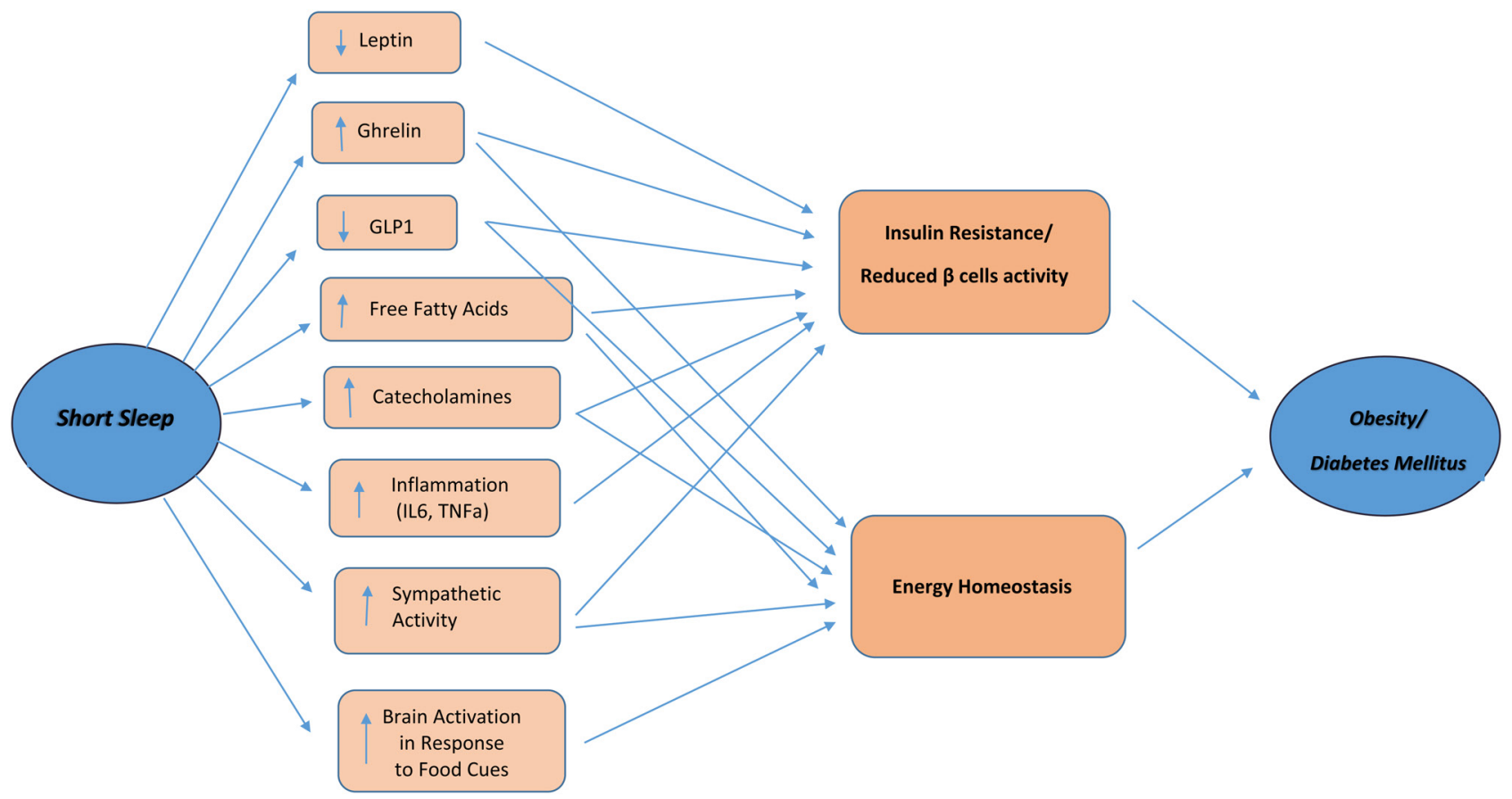

Figure 1

The mechanisms between short sleep duration and type 2 diabetes mellitus and obesity.

which are reversed with sleep extension (Spiegel et al. 2004, Knutson etal. 2007, Zhu etal. 2019). This was also confirmed in a recent systematic review (Zhu et al. 2019). This systematic review also showed that partial sleep restriction is also associated with increased calorie intake $(259 \mathrm{kcal} /$ day, 95\%CI, 59.08-446.53). The increased appetite seems to be particularly related to higher glycaemic index, glycaemic load (particularly consumption of significantly more desserts and sweets) and carbohydrate intake although other studies also showed increased appetite for fat intake (Beebe et al. 2013, Yang et al. 2019, Zhu et al. 2019). Some studies also showed that short sleep duration is associated with less physical activity (Schmid et al. 2009). However, a recent meta-analysis showed that total and partial sleep restriction had no impact on resting or total energy expenditure including some studies using doubly labelled water method (Zhu et al. 2019). Also, the study of Patterson et al. showed that compared to those sleeping $\leq 6$ $\mathrm{h}$ /day, adults who reported $\geq 9 \mathrm{~h}$ sleep consumed 178 fewer $\mathrm{kcal} /$ day. Compared to those with $\leq 6 \mathrm{~h} /$ day of sleep, adults who reported $9 \mathrm{~h}$ of usual sleep expended 113 fewer kcal/ day in physical activity (Patterson et al. 2014).

So overall, the links between short sleep duration and obesity seem to be related to an impact on energy consumption rather than energy expenditure.

The mechanisms linking short sleep to increased energy consumption are multiple including changes in the hormones that regulate energy homeostasis (detailed in the next section). In addition, people with short sleep duration have 'more awake hours' available which are likely to lead to positive energy balance. Another important link between short sleep and increased energy intake is the impact of sleep restriction or short sleep on brain activity in response to food cues. Sleep restriction is associated with greater activation of brain networks involved in reward (Zhu et al. 2019). Sleep restriction also reduced cognitive control and activity in cortical brain regions leading to selection of foods most capable of triggering weight gain (Greer et al. 2013).

\section{Hormonal changes}

Habitual short sleep duration has been shown to be associated with increased ghrelin/leptin ratio (Taheri et al. 2004, Chaput et al. 2007a, Knutson et al. 2007, Lin et al. 2020). Indeed, the latest meta-analysis at the field showed that participants with short sleep duration had $14 \%$ higher levels of ghrelin compared to participants with normal sleep duration (Lin et al. 2020). Sleep restriction found to be associated with higher levels of endocannabinoids (Jager \& Witkamp 2014). The endocannabinoids system (eCB) governs food intake and hedonic hunger, leading to food overconsuming, positive energy balance and weight gain (Reutrakul \& Van Cauter 2018). Furthermore, 
evidence indicates that $\mathrm{eCB}$ overactivation may lead to ß-cell dysfunction and thus, T2DM (Gruden et al. 2016). Experimental sleep restriction was also associated with reduction in glucagon-like peptide-1 (GLP-1) in women (St-Onge et al. 2012). These changes in leptin, ghrelin and GLP-1 can contribute to the increase appetite and hunger observed in people with habitual short sleep duration and/ or forced sleep restriction.

The impact of sleep on cortisol secretion is another plausible mechanism linking sleep duration to obesity and T2DM. Glucocorticoids secretion is increased mainly around the onset of awaking and dropped down during sleep (Balbo et al. 2010). This pattern found to be different in chronic sleep restriction, with levels to be higher during evening,(Guyon et al. 2014), an increase in the nadir levels, a delay in the phase of the cortisol rhythm and a lower rate of decline (Rao et al. 2021). All these could lead to disturbance of the glucose-insulin metabolism, substrate oxidation and obesity. On the other hand, long sleep acts favourably protecting older adults from exhibiting increases in diurnal cortisol secretion over time (Rueggeberg et al. 2012).

Inflammation plays a role in the pathogenesis of T2DM and can affect both insulin resistance and secretion (Akash et al. 2013). Short sleep duration has been associated with increase inflammatory cytokines such as interleukin-6 and tumour necrosis factor a (Vgontzas et al. 2004, Patel et al. 2009, van Leeuwen et al. 2009). Short sleep duration was found also to be associated with elevated CRP, gammaglutamyl transferase, uric acid and vitamin A levels but lower bilirubin, carotenoids and vitamin C, D and E levels. This observation shows once again the important role of sleep duration in inflammation and oxidate stress.

There is a relationship between sex hormones and sleep duration. Women reporting night/shift work had lower testosterone relative to women employed without night/shift work, while for every hour increase in daily sleep duration, mean estradiol concentrations increased by $3.9 \%$ and luteal phase progesterone by $9.4 \%$ (Michels et al. 2020). These changes could contribute to the links between menopause and obesity (Sørensen 2002).

\section{Insulin secretion and resistance}

Experimental studies showed that sleep restriction was associated with reduced insulin sensitivity without compensatory increase in insulin secretion suggesting impaired $\beta$-cell function in people without T2DM (Morselli et al. 2010, Zhu et al. 2019). However, these associations seems to be mainly present in men rather than women, in fact in women, short sleep duration has been associated with improved insulin sensitivity (Wong et al. 2015, Rutters et al. 2016). There are no clear explanations for these gender differences, but interestingly, the links between short sleep duration and the risk for developing T2DM were much stronger in men vs women in a large meta-analysis (Itani et al. 2017). The reduction in insulin sensitivity has been shown to be mainly related to peripheral rather than hepatic insulin resistance (Rao et al. 2015). Insulin resistance may also be the result of abnormal adipocyte function, as four nights of sleep restriction resulted in approximately 30\% reduction in cellular insulin signaling in adipocytes (Broussard et al. 2012).

The impact of sleep duration on insulin sensitivity and $\beta$-cell function can be due to multiple mechanisms. Habitual short sleep duration and experimental sleep restriction are associated with sympathetic predominance either to reduced vagal tone or increased sympathetic activity (Castro-Diehl et al. 2016, van Leeuwen et al. 2018). Increased sympathetic activity can lower response of $\beta$-cells to glucose and reduce insulin sensitivity (Bloom et al. 1978, Kahn et al. 2006, Faber et al. 2020).

A recent meta-analysis has examined the relationship between sleep duration and leptin. Short sleepers (vs normal sleepers) had greater leptin levels in the experimental subgroup analysis $(\mathrm{SMD}=0.19,95 \% \mathrm{CI}$ $(0.03,0.35))$ and greater ghrelin level in the cross-sectional subgroup analysis $(\mathrm{SMD}=0.14,95 \%$ CI $(0.02,0.27)$ ) (Lin et al. 2020).

Experimental sleep restriction is also associated with increased free fatty acids, which can lead to insulin resistance and hyperglycaemia by increasing gluconeogenesis (Chen et al. 1999, Boden et al. 2001, Broussard et al. 2015). In addition, sleep restriction is associated with several hormonal changes that can have an impact on insulin resistance and secretion including prolonged nocturnal growth hormone secretion as well as early increased morning noradrenaline and adrenaline (Broussard et al. 2015). Short sleep duration (experimental and habitual) has been associated with activation of the hypothalamic pituitary adrenal axis (Plat et al. 1999, Abell et al. 2016, Walsh et al. 2019).

\section{Conclusion}

Short sleep duration is an independent risk factor for the development of obesity and T2DM. Short sleep also have been shown to worsen the outcomes of weight loss treatments in small studies. Changes in sleep duration had favourable impact on weight in some but not all

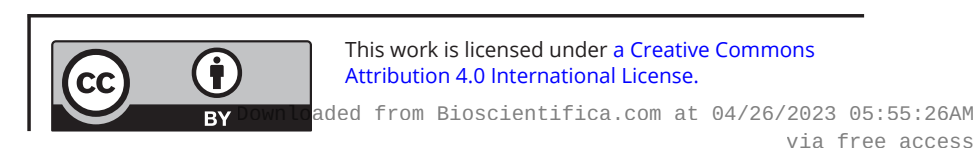


studies and had no beneficial impact on the risk of T2DM. Several plausible mechanisms might explain the links between sleep, obesity and T2DM via changes in energy homeostasis, insulin resistance and beta-cell function.

Several studies showed that sleep manipulation is achievable. Whether sleep manipulation can prevent obesity or T2DM is currently unknown and needs to be examined. Early evidence suggests that sleep manipulation has favourable impact on weight loss or body composition as a part of lifestyle intervention (calorie restriction), but well-conducted long-term RCTs are needed to examine the role of sleep manipulation during weight loss treatments (lifestyle, pharmacotherapy, bariatric surgery). Similarly, the impact of sleep manipulation in patients with T2DM needs to be examined.

\section{Supplementary materials}

This is linked to the online version of the paper at https://doi.org/10.1530/ JOE-21-0155.

\section{Declaration of interest}

Dr Tahrani reports grants from Novo Nordisk, personal fees from Novo Nordisk, non-financial support from Novo Nordisk, personal fees from Eli Lilly, non-financial support from Eli Lilly, personal fees from Janssen, personal fees from $A Z$, non-financial support from $A Z$, non-financial support from Impeto medical, non-financial support from Resmed, non-financial support from Aptiva, personal fees from Bl, non-financial support from $\mathrm{BI}$, personal fees from BMS, nonfinancial support from BMS, personal fees from NAPP, non-financial support from NAPP, personal fees from MSD, non-financial support from MSD, personal fees from Nestle, personal fees from Gilead, grants from Sanofi, and personal fees from Sanofi outside the submitted work. A A T is currently an employee of Novo Nordisk. This work was performed before A A T becoming a Novo Nordisk employee and Novo Nordisk had no role in this project. The other authors have nothing to disclose.

\section{Funding}

This work did not receive any specific grant from any funding agency in the public, commercial, or not-for-profit sector.

\section{Author contribution statement}

CA and GK drafted the manuscript. CA, GK, KN and AAT critically appraised the paper. KN and AAT proposed the idea. MS, KN and AAT gave final suggestions. All authors contributed to the final approval of the manuscript.

\section{References}

Abell JG, Shipley MJ, Ferrie JE, Kivimäki M \& Kumari M 2016 Recurrent short sleep, chronic insomnia symptoms and salivary cortisol: a 10-year follow-up in the Whitehall II study. Psychoneuroendocrinology 68 91-99. (https://doi.org/10.1016/j.psyneuen.2016.02.021)
Akash MS, Rehman K \& Chen S 2013 Role of inflammatory mechanisms in pathogenesis of type 2 diabetes mellitus. Journal of Cellular Biochemistry 114 525-531. (https://doi.org/10.1002/jcb.24402)

Al Khatib HK, Hall WL, Creedon A, Ooi E, Masri T, McGowan L, Harding SV, Darzi J \& Pot GK 2018 Sleep extension is a feasible lifestyle intervention in free-living adults who are habitually short sleepers: a potential strategy for decreasing intake of free sugars? A randomized controlled pilot study. American Journal of Clinical Nutrition 107 43-53. (https://doi.org/10.1093/ajcn/nqx030)

Anothaisintawee T, Reutrakul S, Van Cauter E \& Thakkinstian A 2016 Sleep disturbances compared to traditional risk factors for diabetes development: systematic review and meta-analysis. Sleep Medicine Reviews 30 11-24. (https://doi.org/10.1016/j.smrv.2015.10.002)

Asad Z, Abbas M, Javed I, Korantzopoulos P \& Stavrakis S 2018 Obesity is associated with incident atrial fibrillation independent of gender: a meta-analysis. Journal of Cardiovascular Electrophysiology 29 725-732. (https://doi.org/10.1111/jce.13458)

Bacaro V, Ballesio A, Cerolini S, Vacca M, Poggiogalle E, Donini LM, Lucidi F \& Lombardo C 2020 Sleep duration and obesity in adulthood: an updated systematic review and meta-analysis. Obesity Research and Clinical Practice 14 301-309. (https://doi.org/10.1016/j. orcp.2020.03.004)

Balbo M, Leproult R \& Van Cauter E 2010 Impact of sleep and its disturbances on hypothalamo-pituitary-adrenal axis activity. International Journal of Endocrinology 2010 759234. (https://doi. org/10.1155/2010/759234)

Basch CE, Basch CH, Ruggles KV \& Rajan S 2014 Prevalence of sleep duration on an average school night among 4 nationally representative successive samples of American high school students, 2007-2013. Preventing Chronic Disease 11 E216-E216. (https://doi.org/10.5888/ pcd11.140383)

Beebe DW, Simon S, Summer S, Hemmer S, Strotman D \& Dolan LM 2013 Dietary intake following experimentally restricted sleep in adolescents. Sleep 36 827-834. (https://doi.org/10.5665/sleep.2704)

Blackman A, Foster GD, Zammit G, Rosenberg R, Aronne L, Wadden T, Claudius B, Jensen CB \& Mignot E 2016 Effect of liraglutide $3.0 \mathrm{mg}$ in individuals with obesity and moderate or severe obstructive sleep apnea: the SCALE Sleep Apnea randomized clinical trial. International Journal of Obesity 40 1310-1319. (https://doi.org/10.1038/ijo.2016.52)

Bloom SR, Edwards AV \& Hardy RN 1978 The role of the autonomic nervous system in the control of glucagon, insulin and pancreatic polypeptide release from the pancreas. Journal of Physiology 280 9-23. (https://doi.org/10.1113/jphysiol.1978.sp012369)

Boden G, Lebed B, Schatz M, Homko C \& Lemieux S 2001 Effects of acute changes of plasma free fatty acids on intramyocellular fat content and insulin resistance in healthy subjects. Diabetes 50 1612-1617. (https:// doi.org/10.2337/diabetes.50.7.1612)

Broussard JL, Ehrmann DA, Van Cauter E, Tasali E \& Brady MJ 2012 Impaired insulin signaling in human adipocytes after experimental sleep restriction: a randomized, crossover study. Annals of Internal Medicine 157 549-557. (https://doi.org/10.7326/0003-4819-157-8201210160-00005)

Broussard JL, Chapotot F, Abraham V, Day A, Delebecque F, Whitmore HR \& Tasali E 2015 Sleep restriction increases free fatty acids in healthy men. Diabetologia 58 791-798. (https://doi.org/10.1007/s00125-0153500-4)

Brownrigg JRW, Hughes CO, Burleigh D, Karthikesalingam A, Patterson BO, Holt PJ, Thompson MM, de Lusignan S, Ray KK \& Hinchliffe RJ 2016 Microvascular disease and risk of cardiovascular events among individuals with type 2 diabetes: a population-level cohort study. Lancet: Diabetes and Endocrinology 4 588-597. (https://doi.org/10.1016/ S2213-8587(16)30057-2)

Capers PL, Fobian AD, Kaiser KA, Borah R \& Allison DB 2015 A systematic review and meta-analysis of randomized controlled trials of the impact of sleep duration on adiposity and components of energy balance. Obesity Reviews 16 771-782. (https://doi.org/10.1111/obr.12296) 
Cappuccio FP, D’Elia L, Strazzullo P \& Miller MA 2010 Quantity and quality of sleep and incidence of type 2 diabetes: a systematic review and metaanalysis. Diabetes Care 33 414-420. (https://doi.org/10.2337/dc09-1124)

Castro-Diehl C, Diez Roux AV, Redline S, Seeman T, McKinley P, Sloan R $\&$ Shea S 2016 Sleep duration and quality in relation to autonomic nervous system measures: the multi-ethnic study of atherosclerosis (MESA). Sleep 39 1927-1940. (https://doi.org/10.5665/sleep.6218)

Cespedes EM, Bhupathiraju SN, Li Y, Rosner B, Redline S \& Hu FB $2016 a$ Long-term changes in sleep duration, energy balance and risk of type 2 diabetes. Diabetologia 59 101-109. (https://doi.org/10.1007/s00125015-3775-5)

Cespedes EM, Hu FB, Redline S, Rosner B, Alcantara C, Cai J, Hall MH, Loredo JS, Mossavar-Rahmani Y, Ramos AR, et al. 2016b Comparison of self-reported sleep duration with actigraphy: results from the Hispanic Community Health Study/Study of Latinos Sueño Ancillary Study. American Journal of Epidemiology 183 561-573. (https://doi.org/10.1093/ aje/kwv251)

Chaput JP \& Tremblay A 2012 Sleeping habits predict the magnitude of fat loss in adults exposed to moderate caloric restriction. Obesity Facts 5 561-566. (https://doi.org/10.1159/000342054)

Chaput JP, Després JP, Bouchard C \& Tremblay A 2007a Short sleep duration is associated with reduced leptin levels and increased adiposity: results from the Quebec family study. Obesity 15 253-261. (https://doi.org/10.1038/oby.2007.512)

Chaput JP, Després JP, Bouchard C \& Tremblay A 2007b Association of sleep duration with type 2 diabetes and impaired glucose tolerance. Diabetologia 50 2298-2304. (https://doi.org/10.1007/s00125-0070786-x)

Chaput JP, Després JP, Bouchard C \& Tremblay A 2012 Longer sleep duration associates with lower adiposity gain in adult short sleepers. International Journal of Obesity 36 752-756. (https://doi.org/10.1038/ ijo.2011.110)

Chen X, Iqbal N \& Boden G 1999 The effects of free fatty acids on gluconeogenesis and glycogenolysis in normal subjects. Journal of Clinical Investigation 103 365-372. (https://doi.org/10.1172/JCI5479)

Chong Y, Fryer CD \& Gu Q 2013 Prescription sleep aid use among adults: United States, 2005-2010. NCHS Data Brief, no.127. Hyattsville MD; National Center for Health Statistics. 1-8.(https://www.cdc.gov/nchs/ data/databriefs/db127.pdf )

Deng X, He M, He D, Zhu Y, Zhang Z \& Niu W 2021 Sleep duration and obesity in children and adolescents: evidence from an updated and dose-response meta-analysis. Sleep Medicine 78 169-181. (https://doi. org/10.1016/j.sleep.2020.12.027)

Douglas PS \& Hill PS 2013 Behavioral sleep interventions in the first six months of life do not improve outcomes for mothers or infants: a systematic review. Journal of Developmental and Behavioral Pediatrics 34 497-507. (https://doi.org/10.1097/DBP.0b013e31829cafa6)

Engeda J, Mezuk B, Ratliff S \& Ning Y 2013 Association between duration and quality of sleep and the risk of pre-diabetes: evidence from NHANES. Diabetic Medicine 30 676-680. (https://doi.org/10.1111/ dme.12165)

Faber CL, Deem JD, Campos CA, Taborsky GJ \& Morton GJ 2020 CNS control of the endocrine pancreas. Diabetologia 63 2086-2094. (https:// doi.org/10.1007/s00125-020-05204-6)

Fatima Y, Doi SA \& Mamun AA 2015 Longitudinal impact of sleep on overweight and obesity in children and adolescents: a systematic review and bias-adjusted meta-analysis. Obesity Reviews 16 137-149. (https://doi.org/10.1111/obr.12245)

Ferrie JE, Kivimäki M, Akbaraly TN, Tabak A, Abell J, Davey Smith G, Virtanen M, Kumari M \& Shipley MJ 2015 Change in sleep duration and Type 2 diabetes: the Whitehall II study. Diabetes Care 38 1467-1472. (https://doi.org/10.2337/dc15-0186)

France KG, McLay LK, Hunter JE \& France MLS 2018 Empirical research evaluating the effects of non-traditional approaches to enhancing sleep in typical and clinical children and young people. Sleep Medicine Reviews 39 69-81. (https://doi.org/10.1016/j.smrv.2017.07.004)
Gangwisch JE, Malaspina D, Boden-Albala B \& Heymsfield SB 2005 Inadequate sleep as a risk factor for obesity: analyses of the NHANES I. Sleep 28 1289-1296. (https://doi.org/10.1093/sleep/28.10.1289)

Global Burden of Metabolic Risk Factors for Chronic Diseases Collaboration (BMI Mediated Effects), Lu Y, Hajifathalian K, Ezzati M, Woodward M, Rimm EB \& Danaei G 2014 Metabolic mediators of the effects of body-mass index, overweight, and obesity on coronary heart disease and stroke: a pooled analysis of 97 prospective cohorts with 1.8 million participants. Lancet 383 970-983. (https://doi.org/10.1016/ S0140-6736(13)61836-X)

Gordon S, Vandelanotte C, Rayward AT, Murawski B \& Duncan MJ 2019 Sociodemographic and behavioral correlates of insufficient sleep in Australian adults. Sleep Health 5 12-17. (https://doi.org/10.1016/j. sleh.2018.06.002)

Greer SM, Goldstein AN \& Walker MP 2013 The impact of sleep deprivation on food desire in the human brain. Nature Communications 42259. (https://doi.org/10.1038/ncomms3259)

Gruden G, Barutta F, Kunos G \& Pacher P 2016 Role of the endocannabinoid system in diabetes and diabetic complications. British Journal of Pharmacology 173 1116-1127. (https://doi.org/10.1111/bph.13226)

Guh DP, Zhang W, Bansback N, Amarsi Z, Birmingham CL \& Anis AH 2009 The incidence of co-morbidities related to obesity and overweight: a systematic review and meta-analysis. BMC Public Health 9 88-88. (https://doi.org/10.1186/1471-2458-9-88)

Guo Y, Miller MA \& Cappuccio FP 2021 Short duration of sleep and incidence of overweight or obesity in Chinese children and adolescents: a systematic review and meta-analysis of prospective studies. Nutrition, Metabolism, and Cardiovascular Diseases 31 363-371. (https://doi.org/10.1016/j.numecd.2020.11.001)

Guyon A, Balbo M, Morselli LL, Tasali E, Leproult R, L'Hermite-Balériaux M, Van Cauter E \& Spiegel K 2014 Adverse effects of two nights of sleep restriction on the hypothalamic-pituitary-adrenal axis in healthy men. Journal of Clinical Endocrinology and Metabolism 99 2861-2868. (https:// doi.org/10.1210/jc.2013-4254)

Haack M, Serrador J, Cohen D, Simpson N, Meier-Ewert H \& Mullington JM 2013 Increasing sleep duration to lower beat-to-beat blood pressure: a pilot study. Journal of Sleep Research 22 295-304. (https://doi. org/10.1111/jsr.12011)

Halal CS \& Nunes ML 2014 Education in children's sleep hygiene: which approaches are effective? A systematic review. Jornal de Pediatria 90 449-456. (https://doi.org/10.1016/j.jped.2014.05.001)

Henst RHP, Pienaar PR, Roden LC \& Rae DE 2019 The effects of sleep extension on cardiometabolic risk factors: a systematic review 28. Journal of Sleep Research 28 e12865. (https://doi.org/10.1111/jsr.12865)

Holliday EG, Magee CA, Kritharides L, Banks E \& Attia J 2013 Short sleep duration is associated with risk of future diabetes but not cardiovascular disease: a prospective study and meta-analysis. PLoS ONE 8 e82305. (https://doi.org/10.1371/journal.pone.0082305)

Itani O, Jike M, Watanabe N \& Kaneita Y 2017 Short sleep duration and health outcomes: a systematic review, meta-analysis, and metaregression. Sleep Medicine 32 246-256. (https://doi.org/10.1016/j. sleep.2016.08.006)

Jackson CL, Patel SR, Jackson WB, II, Lutsey PL \& Redline S 2018 Agreement between self-reported and objectively measured sleep duration among white, black, Hispanic, and Chinese adults in the United States: multi-ethnic study of atherosclerosis. Sleep $\mathbf{4 1}$ zsy057. (https://doi. org/10.1093/sleep/zsy057)

Jager G \& Witkamp RF 2014 The endocannabinoid system and appetite: relevance for food reward. Nutrition Research Reviews 27 172-185. (https://doi.org/10.1017/S0954422414000080)

Jee D, Keum N, Kang S \& Arroyo JG 2017 Sleep and diabetic retinopathy. Acta Ophthalmologica 95 41-47. (https://doi.org/10.1111/aos.13169)

Jike M, Itani O, Watanabe N, Buysse DJ \& Kaneita Y 2018 Long sleep duration and health outcomes: a systematic review, meta-analysis and meta-regression. Sleep Medicine Reviews 39 25-36. (https://doi org/10.1016/j.smrv.2017.06.011)

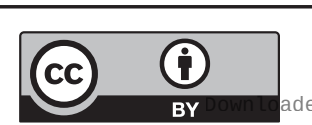

This work is licensed under a Creative Commons Attribution 4.0 International License. Atrom Bioscientifica com at $04 / 26 / 2023$ 05:55:26AM 
Jones AP, Homer JB, Murphy DL, Essien JD, Milstein B \& Seville DA 2006 Understanding diabetes population dynamics through simulation modeling and experimentation. American Journal of Public Health 96 488-494. (https://doi.org/10.2105/AJPH.2005.063529)

Kahn SE, Hull RL \& Utzschneider KM 2006 Mechanisms linking obesity to insulin resistance and type 2 diabetes. Nature $\mathbf{4 4 4}$ 840-846. (https:// doi.org/10.1038/nature05482)

Killick R, Hoyos CM, Melehan KL, Dungan GC, 2nd, Poh J \& Liu PY 2015 Metabolic and hormonal effects of 'catch-up' sleep in men with chronic, repetitive, lifestyle-driven sleep restriction. Clinical Endocrinology 83 498-507. (https://doi.org/10.1111/cen.12747)

Knowlden AP, Hackman CL \& Sharma M 2016 Systematic review of dietary interventions targeting sleep behavior. Journal of Alternative and Complementary Medicine 22 349-362. (https://doi.org/10.1089/ acm.2015.0238)

Knutson KL, Spiegel K, Penev P \& Van Cauter E 2007 The metabolic consequences of sleep deprivation. Sleep Medicine Reviews 11 163-178. (https://doi.org/10.1016/j.smrv.2007.01.002)

Koch S, Haesler E, Tiziani A \& Wilson J 2006 Effectiveness of sleep management strategies for residents of aged care facilities: findings of a systematic review. Journal of Clinical Nursing 15 1267-1275. (https://doi. org/10.1111/j.1365-2702.2006.01385.x)

Kripke DF, Langer RD \& Kline LE 2012 Hypnotics' association with mortality or cancer: a matched cohort study. BMJ Open $\mathbf{2}$ e000850. (https://doi.org/10.1136/bmjopen-2012-000850)

Langford DJ, Lee K \& Miaskowski C 2012 Sleep disturbance interventions in oncology patients and family caregivers: a comprehensive review and meta-analysis. Sleep Medicine Reviews 16 397-414. (https://doi. org/10.1016/j.smrv.2011.07.002)

Lavrentaki A, Ali A, Cooper BG \& Tahrani AA 2019 MECHANISMS OF ENDOCRINOLOGY: Mechanisms of disease: the endocrinology of obstructive sleep apnoea. European Journal of Endocrinology 180 R91-R125. (https://doi.org/10.1530/EJE-18-0411)

Lee SWH, Ng KY \& Chin WK 2017 The impact of sleep amount and sleep quality on glycemic control in type 2 diabetes: a systematic review and meta-analysis. Sleep Medicine Reviews 31 91-101. (https://doi. org/10.1016/j.smrv.2016.02.001)

Leproult R, Deliens G, Gilson M \& Peigneux P 2015 Beneficial impact of sleep extension on fasting insulin sensitivity in adults with habitual sleep restriction. Sleep 38 707-715. (https://doi.org/10.5665/ sleep.4660)

Li L, Zhang S, Huang Y \& Chen K 2017 Sleep duration and obesity in children: a systematic review and meta-analysis of prospective cohort studies. Journal of Paediatrics and Child Health 53 378-385. (https://doi. org/10.1111/jpc.13434)

Lin J, Jiang Y, Wang G, Meng M, Zhu Q, Mei H, Liu S \& Jiang F 2020 Associations of short sleep duration with appetite-regulating hormones and adipokines: a systematic review and meta-analysis. Obesity Reviews 21 e13051. (https://doi.org/10.1111/obr.13051)

Logue EE, Bourguet CC, Palmieri PA, Scott ED, Matthews BA, Dudley P \& Chipman KJ 2012 The better weight-better sleep study: a pilot intervention in primary care. American Journal of Health Behavior 36 319-334. (https://doi.org/10.5993/AJHB.36.3.4)

Meltzer LJ \& Mindell JA 2014 Systematic review and meta-analysis of behavioral interventions for pediatric insomnia. Journal of Pediatric Psychology 39 932-948. (https://doi.org/10.1093/jpepsy/jsu041)

Michels KA, Mendola P, Schliep KC, Yeung EH, Ye A, Dunietz GL, Wactawski-Wende J, Kim K, Freeman JR, Schisterman EF, et al. 2020 The influences of sleep duration, chronotype, and nightwork on the ovarian cycle. Chronobiology International 37 260-271. (https://doi.org/ 10.1080/07420528.2019.1694938)

Miller MA, Bates S, Ji C \& Cappuccio FP 2021 Systematic review and meta-analyses of the relationship between short sleep and incidence of obesity and effectiveness of sleep interventions on weight gain in preschool children. Obesity Reviews 22 e13113. (https://doi.org/ 10.1111/obr.13113)
Milstein B, Jones A, Homer JB, Murphy D, Essien J \& Seville D 2007 Charting plausible futures for diabetes prevalence in the United States: a role for system dynamics simulation modeling. Preventing Chronic Disease 4 A52.(https://www.cdc.gov/pcd/issues/2007/jul/pdf/06_0070. pdf )

Mindell JA, Kuhn B, Lewin DS, Meltzer LJ, Sadeh A \& American Academy of Sleep Medicine 2006 Behavioral treatment of bedtime problems and night wakings in infants and young children. Sleep 29 1263-1276. (https://doi.org/10.1093/sleep/29.10.1263)

Miner B, Stone KL, Zeitzer JM, Han L, Doyle M, Blackwell T, Gill TM, Redeker NS, Hajduk A \& Yaggi HK 2021 Self-reported and actigraphic short sleep duration in older adults. Journal of Clinical Sleep Medicine. (https://doi.org/10.5664/jcsm.9584)

Mistry P, Currie V, Super P, le Roux CW, Tahrani AA \& Singhal R 2018 Changes in glycaemic control, blood pressure and lipids 5 years following laparoscopic adjustable gastric banding combined with medical care in patients with type 2 diabetes: a longitudinal analysis. Clinical Obesity 8 151-158. (https://doi.org/10.1111/cob.12244)

Morselli L, Leproult R, Balbo M \& Spiegel K 2010 Role of sleep duration in the regulation of glucose metabolism and appetite. Best Practice and Research: Clinical Endocrinology and Metabolism 24 687-702. (https:// doi.org/10.1016/j.beem.2010.07.005)

NCD Risk Factor Collaboration (NCD-RisC), Abarca-Gómez L, Abdeen ZA, Hamid ZA, Abu-Rmeileh NM, Acosta-Cazares B, Acuin C, Adams RJ, Aekplakorn W, Afsana K, et al. 2017 Worldwide trends in body-mass index, underweight, overweight, and obesity from 1975 to 2016: a pooled analysis of 2416 population-based measurement studies in 128.9 million children, adolescents, and adults. Lancet 390 2627-2642. (https://doi.org/10.1016/S0140-6736(17)32129-3)

Nedeltcheva AV, Kilkus JM, Imperial J, Schoeller DA \& Penev PD 2010 Insufficient sleep undermines dietary efforts to reduce adiposity. Annals of Internal Medicine 153 435-441. (https://doi.org/10.7326/0003-4819153-7-201010050-00006)

Owens J, Group ASW \& Adolescence Co 2014 Insufficient sleep in adolescents and young adults: an update on causes and consequences. Pediatrics 134 e921-e932.(https://doi.org/10.1542/peds.2014-1696 )

Park HK, Kim J \& Shim YS 2020 Association between sleep duration and body composition in girls ten to eighteen years of age: a populationbased study. Childhood Obesity 16 281-290. (https://doi.org/10.1089/ chi.2019.0191)

Patel SR, Zhu X, Storfer-Isser A, Mehra R, Jenny NS, Tracy R \& Redline S 2009 Sleep duration and biomarkers of inflammation. Sleep 32 200-204. (https://doi.org/10.1093/sleep/32.2.200)

Patterson RE, Emond JA, Natarajan L, Wesseling-Perry K, Kolonel LN, Jardack P, Ancoli-Israel S \& Arab L 2014 Short sleep duration is associated with higher energy intake and expenditure among AfricanAmerican and non-Hispanic white adults. Journal of Nutrition 144 461-466. (https://doi.org/10.3945/jn.113.186890)

Plat L, Leproult R, L'Hermite-Baleriaux M, Fery F, Mockel J, Polonsky KS \& Van Cauter E 1999 Metabolic effects of short-term elevations of plasma cortisol are more pronounced in the evening than in the morning. Journal of Clinical Endocrinology and Metabolism 84 3082-3092. (https:// doi.org/10.1210/jcem.84.9.5978)

Rao MN, Neylan TC, Grunfeld C, Mulligan K, Schambelan M \& Schwarz JM 2015 Subchronic sleep restriction causes tissue-specific insulin resistance. Journal of Clinical Endocrinology and Metabolism 100 1664-1671. (https://doi.org/10.1210/jc.2014-3911)

Rao R, Somvanshi P, Klerman EB, Marmar C \& Doyle 3rd FJ 2021 Modeling the influence of chronic sleep restriction on cortisol circadian rhythms, with implications for metabolic disorders. Metabolites 11 483. (https:// doi.org/10.3390/metabo11080483)

Reutrakul S \& Van Cauter E 2018 Sleep influences on obesity, insulin resistance, and risk of type 2 diabetes. Metabolism: Clinical and Experimental 84 56-66. (https://doi.org/10.1016/j.metabol.2018.02.010)

Reutrakul S, Anothaisintawee T, Herring SJ, Balserak BI, Marc I \& Thakkinstian A 2018 Short sleep duration and hyperglycemia in 
pregnancy: aggregate and individual patient data meta-analysis. Sleep Medicine Reviews 40 31-42. (https://doi.org/10.1016/j. smrv.2017.09.003)

Rosique-Esteban N, Papandreou C, Romaguera D, Warnberg J, Corella D, Martínez-González MÁ, Díaz-López A, Estruch R, Vioque J, Arós F, et al. 2018 Cross-sectional associations of objectively-measured sleep characteristics with obesity and type 2 diabetes in the PREDIMED-Plus trial. Sleep 41110.(https://doi.org/10.1093/sleep/zsy190)

Ruan H, Xun P, Cai W, He K \& Tang Q 2015 Habitual sleep duration and risk of childhood obesity: systematic review and dose-response meta-analysis of prospective cohort studies. Scientific Reports 516160. (https://doi.org/10.1038/srep16160)

Rueggeberg R, Wrosch C \& Miller GE 2012 Sleep duration buffers diurnal cortisol increases in older adulthood. Psychoneuroendocrinology 37 1029-1038. (https://doi.org/10.1016/j.psyneuen.2011.11.012)

Rutters F, Besson H, Walker M, Mari A, Konrad T, Nilsson PM, Balkau B $\&$ Dekker JM 2016 The association between sleep duration, insulin sensitivity, and $\beta$-cell function: the EGIR-RISC study. Journal of Clinical Endocrinology and Metabolism 101 3272-3280. (https://doi.org/10.1210/ jc.2016-1045)

Saeedi P, Petersohn I, Salpea P, Malanda B, Karuranga S, Unwin N, Colagiuri S, Guariguata L, Motala AA, Ogurtsova K, et al. 2019 Global and regional diabetes prevalence estimates for 2019 and projections for 2030 and 2045: results from the International Diabetes Federation Diabetes Atlas, 9(th) edition. Diabetes Research and Clinical Practice 157 107843. (https://doi.org/10.1016/j.diabres.2019.107843)

Salm WTC \& Balfour GM 2016 Infant safe sleep interventions, 1990-2015: a review. Journal of Community Health 41 180-196.(https://doi. org/10.1007/s10900-015-0060-y )

Schmid SM, Hallschmid M, Jauch-Chara K, Wilms B, Benedict C, Lehnert H, Born J \& Schultes B 2009 Short-term sleep loss decreases physical activity under free-living conditions but does not increase food intake under time-deprived laboratory conditions in healthy men. American Journal of Clinical Nutrition 90 1476-1482. (https://doi. org/10.3945/ajcn.2009.27984)

Shan Z, Ma H, Xie M, Yan P, Guo Y, Bao W, Rong Y, Jackson CL, Hu FB \& Liu L 2015 Sleep duration and risk of type 2 diabetes: a meta-analysis of prospective studies. Diabetes Care 38 529-537. (https://doi.org/10.2337/ dc14-2073)

Singh P, Subramanian A, Adderley N, Gokhale K, Singhal R, Bellary S, Nirantharakumar K \& Tahrani AA 2020 Impact of bariatric surgery on cardiovascular outcomes and mortality: a population-based cohort study 107. British Journal of Surgery 107 432-442. (https://doi. org/10.1002/bjs.11433)

Song Q, Liu X, Zhou W, Wang X \& Wu S 2016 Short-term changes in sleep duration and risk of type 2 diabetes: Kailuan prospective study. Medicine 95 e5363. (https://doi.org/10.1097/MD.0000000000005363)

Sørensen MB 2002 Changes in body composition at menopause - age, lifestyle or hormone deficiency? Journal of the British Menopause Society 8 137-140. (https://doi.org/10.1258/136218002100321974)

Sperry SD, Scully ID, Gramzow RH \& Jorgensen RS 2015 Sleep duration and waist circumference in adults: a meta-analysis. Sleep 38 1269-1276. (https://doi.org/10.5665/sleep.4906)

Spiegel K, Tasali E, Penev P \& Van Cauter E 2004 Brief communication: sleep curtailment in healthy young men is associated with decreased leptin levels, elevated ghrelin levels, and increased hunger and appetite. Annals of Internal Medicine 141 846-850. (https://doi. org/10.7326/0003-4819-141-11-200412070-00008)

Stamler J, Vaccaro O, Neaton JD \& Wentworth D 1993 Diabetes, other risk factors, and 12-yr cardiovascular mortality for men screened in the Multiple Risk Factor Intervention Trial. Diabetes Care 16 434-444. (https://doi.org/10.2337/diacare.16.2.434)

St-Onge MP, O'Keeffe M, Roberts AL, RoyChoudhury A \& Laferrère B 2012 Short sleep duration, glucose dysregulation and hormonal regulation of appetite in men and women. Sleep 35 1503-1510. (https://doi. org/10.5665/sleep.2198)
Surani S, Brito V, Surani A \& Ghamande S 2015 Effect of diabetes mellitus on sleep quality. World Journal of Diabetes 6 868-873. (https://doi. org/10.4239/wjd.v6.i6.868)

Taheri S, Lin L, Austin D, Young T \& Mignot E 2004 Short sleep duration is associated with reduced leptin, elevated ghrelin, and increased body mass index. PLoS Medicine 1 e62. (https://doi.org/10.1371/journal. pmed.0010062)

Tan NYQ, Chan J, Cheng CY, Wong TY \& Sabanayagam C 2018 Sleep duration and diabetic kidney disease. Frontiers in Endocrinology 9808. (https://doi.org/10.3389/fendo.2018.00808)

Tasali E, Chapotot F, Wroblewski K \& Schoeller D 2014 The effects of extended bedtimes on sleep duration and food desire in overweight young adults: a home-based intervention. Appetite $80220-224$. (https://doi.org/10.1016/j.appet.2014.05.021)

Toyoura M, Miike T, Tajima S, Matsuzawa S \& Konishi Y 2020 Inadequate sleep as a contributor to impaired glucose tolerance: a cross-sectional study in children, adolescents, and young adults with circadian rhythm sleep-wake disorder. Pediatric Diabetes 21 557-564. (https://doi. org/10.1111/pedi.13003)

Van Cauter E \& Knutson KL 2008 Sleep and the epidemic of obesity in children and adults. European Journal of Endocrinology 159 (Supplement 1) S59-S66. (https://doi.org/10.1530/EJE-08-0298)

van Leeuwen WM, Lehto M, Karisola P, Lindholm H, Luukkonen R, Sallinen M, Härmä M, Porkka-Heiskanen T \& Alenius H 2009 Sleep restriction increases the risk of developing cardiovascular diseases by augmenting proinflammatory responses through IL-17 and CRP. PLoS ONE 4 e4589. (https://doi.org/10.1371/journal.pone.0004589)

van Leeuwen WMA, Sallinen M, Virkkala J, Lindholm H, Hirvonen A, Hublin C, Porkka-Heiskanen T \& Härmä M 2018 Physiological and autonomic stress responses after prolonged sleep restriction and subsequent recovery sleep in healthy young men. Sleep and Biological Rhythms 16 45-54. (https://doi.org/10.1007/s41105-017-0122-x)

Verhoef SP, Camps SG, Gonnissen HK, Westerterp KR \& WesterterpPlantenga MS 2013 Concomitant changes in sleep duration and body weight and body composition during weight loss and 3-mo weight maintenance. American Journal of Clinical Nutrition 98 25-31. (https:// doi.org/10.3945/ajcn.112.054650)

Vgontzas AN, Zoumakis E, Bixler EO, Lin HM, Follett H, Kales A \& Chrousos GP 2004 Adverse effects of modest sleep restriction on sleepiness, performance, and inflammatory cytokines. Journal of Clinical Endocrinology and Metabolism 89 2119-2126. (https://doi. org/10.1210/jc.2003-031562)

Walsh CP, Lim A, Marsland AL, Ferrell RE \& Manuck SB 2019 Circulating interleukin-6 concentration covaries inversely with self-reported sleep duration as a function of polymorphic variation in the glucocorticoid receptor. Brain, Behavior, and Immunity 78 21-30. (https://doi. org/10.1016/j.bbi.2019.01.002)

Wong PM, Manuck SB, DiNardo MM, Korytkowski M \& Muldoon MF 2015 Shorter sleep duration is associated with decreased insulin sensitivity in healthy white men. Sleep 38 223-231. (https://doi.org/10.5665/sleep.4402)

Wu Y, Zhai L \& Zhang D 2014 Sleep duration and obesity among adults: a meta-analysis of prospective studies. Sleep Medicine 15 1456-1462. (https://doi.org/10.1016/j.sleep.2014.07.018)

Wu Y, Gong Q, Zou Z, Li H \& Zhang X 2017 Short sleep duration and obesity among children: a systematic review and meta-analysis of prospective studies. Obesity Research and Clinical Practice 11 140-150. (https://doi.org/10.1016/j.orcp.2016.05.005)

Xu YH, Shi L, Bao YP, Chen SJ, Shi J, Zhang RL \& Lu L 2018 Association between sleep duration during pregnancy and gestational diabetes mellitus: a meta-analysis. Sleep Medicine 52 67-74. (https://doi. org/10.1016/j.sleep.2018.07.021)

Yan LX, Chen XR, Chen B, Bai YM, Li JH, Zhang XW, Dong Z, Wang H, Mi SQ \& Zhao WH 2017 Gender-specific association of sleep duration with body mass index, waist circumference, and body fat in Chinese adults. Biomedical and Environmental Sciences 30 157-169. (https://doi. $\operatorname{org} / 10.3967 /$ bes2017.023)

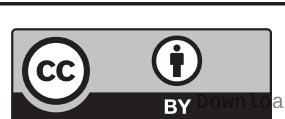

This work is licensed under a Creative Commons Attribution 4.0 International License. 
Yang CL, Schnepp J \& Tucker RM 2019 Increased hunger, food cravings, food reward, and portion size selection after sleep curtailment in women without obesity. Nutrients 11 663. (https://doi.org/10.3390/ nu11030663)

Zheng R, Zhou D \& Zhu Y 2016 The long-term prognosis of cardiovascular disease and all-cause mortality for metabolically healthy obesity: a systematic review and meta-analysis. Journal of Epidemiology and Community Health 70 1024-1031. (https://doi.org/10.1136/jech2015-206948)

Zhou Q, Zhang M \& Hu D 2019 Dose-response association between sleep duration and obesity risk: a systematic review and meta-analysis of prospective cohort studies. Sleep and Breathing 23 1035-1045. (https:// doi.org/10.1007/s11325-019-01824-4)
Zhou Q, Wu X, Zhang D, Liu L, Wang J, Cheng R, Lin J, Liu Y, Sun X, Yin Z, et al. 2020 Age and sex differences in the association between sleep duration and general and abdominal obesity at 6-year follow-up: the rural Chinese cohort study. Sleep Medicine 69 71-77. (https://doi. org/10.1016/j.sleep.2019.12.025)

Zhu B, Shi C, Park CG, Zhao X \& Reutrakul S 2019 Effects of sleep restriction on metabolism-related parameters in healthy adults: a comprehensive review and meta-analysis of randomized controlled trials. Sleep Medicine Reviews 45 18-30. (https://doi.org/10.1016/j.smrv.2019.02.002)

Zuraikat FM, Thomas E, Roeshot D, Gallagher D \& St-Onge MP 2019 Can healthy sleep improve long-term bariatric surgery outcomes? Results of a pilot study and call for further research. Obesity 27 1769-1771. (https://doi.org/10.1002/oby.22601)

Received in final form 14 October 2021

Accepted 12 November 2021

Accepted Manuscript published online 15 November 2021 (c) 2021 The authors Published by Bioscientifica Ltd. Printed in Great Britain
This work is licensed under a Creative Commons Attribution 4.0 International License.

ded from Bioscientifica.com at 04/26/2023 05:55:26AM 